\title{
Analysis on the College Students' Ideological and Political Education Effectiveness under New Media Era
}

\author{
Jingyi Zhang ${ }^{1, a}$ \\ ${ }^{1}$ Institute of Education Chifeng University ,024000,China \\ aemail:12886598@qq.com
}

Keywords: New media era; College students; Ideological and political education; Effectiveness

\begin{abstract}
With the rapid development of modern information technology, based on the Internet, smart phones and other digital information transmission era of new media corresponding got rapid development, at the same time the new media affect the modern human life, work and study, and the contemporary college students is the focus group, use these new media resources. Therefore, in the ideological and political education in colleges and universities should make full use of new media resources, and correctly guide the contemporary college students' way of thinking, will be the perfect unifies in together and it gives full play to the educational function of university's ideology and politics education. This article mainly discusses the concept of new media and its transmission characteristics. The systematic comprehensively analyzes opportunities and challenges of the college students' ideological and political education under the new media era. Combining work reality, the ideological and political education workers think should make full use of new media.
\end{abstract}

\section{Introduction}

The concept of new media is compared with the traditional media; it is in the newspapers, television, radio and other traditional media, the digital technology and communication needs of people of a new kind of ac transmission mode. In this era, the Internet has become the ideological and political education information of the force of public opinion and society, and its influence on ideological and political education also has two sides. On the one hand, it can spread to people rich vivid correct ideological and political education information to help people form a positive world outlook, the outlook on life, values, and services for the ideological and political education. On the other hand, it makes the ideological and political education environment is more complicated, so the ideological and political education put forward a series of new challenges. New media with different from the traditional media of virtual sex, timeliness, interactivity and the characteristics of integration, quickly got widely recognized and accepted, students groups to be the preferred channel they understand information consultation, and profoundly affects their ideology and behavior habits. Face the surging wave of new media, only to analyze college students' ideological and political education work, the new changes and challenges, and innovative methods and means, to effectively improve the pertinence and effectiveness of the ideological and political education work.

\section{The connotation and characteristics of new media}

New media is compared with the traditional media. Is refers to the so-called traditional media newspapers, TV, radio and other news media for media, and new media is based on the information technology, through the Internet, wireless communication technology, the use of multimedia computer, smart phone, as a route of transmission, such as for human life, study, work, communication and other media platform to provide information and services. New media is the most major characteristic is the timeliness of passing information. Because it uses modern information technology, it can in a short period of time will all aspects of data information processing, integration, passed out in time, to achieve the exchange of information. And traditional media such as newspapers, due to its own characteristics, from information collection, page layout, publishing, sales of fixed point and a series of process before into the hands of the people to read and watch, may lead to some news at this time because of time problem may have lost publicity 
necessity of this kind of phenomenon to appear. However, in the new media environment of this kind of problem will not appear. Because the new media is not limited by time and space, can timely information transfer and communication.

\section{The opportunities of the ideological and political education under new media}

New media has enriched the ideological and political education resources and promote the sharing of resources. Today, the Internet has become a cultural information collection and distribution center, college students can break through the traditional education resource constraints, such as using the Internet and other new media, learn advanced scientific theories, absorb all outstanding cultural achievements of human civilization, constantly optimize their knowledge structure and enhance the level of thought and theory. In the era of new media, both ideological and political education workers and college students as audience, can be in the open network system obtain abundant education resources. At the same time, with the help of a network of new media, between the teachers and students and teachers can carry out education resource sharing, can also be a timely communication and ideological debate, finally reached a further understanding and the understanding of the relevant theories of ideological and political education.

New media technology to further enrich the means of ideological and political education. The new media era, SMS, E-mail, QQ, network BBS, Microblog, and Wechat etc. With its convenient, vivid, flexible characteristic gradually become new methods of ideological and political education. Educators' use of new media, can in the shortest possible time, through the text, images, sound, video and other more intuitive and vivid way of communication, to convey the education content to the educates. College students can get the required knowledge through new media anytime and anywhere, not according to the traditional way to the place specified in the stipulation time accept education, provides the convenience for both teachers and students, and enriched the means of ideological and political education.

The new media to enhance the college students' autonomy in the process of ideological and political education. Education is communication, dialogue and understanding between subject and object, and in the era of traditional media, by most educators are in passive audience position of one-way infusion, channel one-way, form a single, weak selectivity. But in the era of new media, new media technology on the transmission form and content has a strong intuitive, vivid and entertaining, make a serious content of ideological and political education, enhance the education of the appeal, educate can relaxed environment, freedom to choose to browse information, seeking new visual auditory content in active exploration and make the effect of ideological and political education in the process of osmosis and rising. At the same time, new media has a strong interactivity, greatly promote the communication and mutual interaction of the educators and the educated, from one-way passive multidirectional interactive shift, able to attract more educated, active participation is improved, thus to enhance the autonomy in the process of college students in ideological and political education.

\section{The new challenge of college students' ideological and political education under new media era}

College students' ideological and political education work environment, new features to the college students' ideological and political education work has brought many new challenges.

The "decentralized" affect college students' value choice and judgment. The new media era is the era of individuality has been fully developed, is the age of diversification of information dissemination. Freely in the physiological and psychological maturity of college students, no center to participate in the communication, become the subject and words as the main body of information way. The rapid development of new media makes the information transmission path and the form has had the fundamental change, the characteristics of "decentralization". Is unable to avoid the real problem is that because of commercial interests of the network media in pursuit of "eyeball economy", revealed the profit-seeking nature of "economic man", the serious destruction 
professional image, and social responsibility, break through the moral bottom line. At the same time, domestic or foreign reactionary forces time to use new media spreading rumors, inverted, confusing, advocating westernization, attempts to achieve against the government, sedition, subversion hidden purpose of our country's regime. The serious influence the young college students' value choice and judgment. College students like fresh things, the pursuit of fashion and stimulation, but right from wrong, true and false, and to judge of good and evil, beauty and ugliness, correct cognition and ability is not strong, easy to artificial misleading as a standard to follow blindly, and have fun, it's made the problem to the college students' ideological education work.

"The authority" weakens the dominant discourse of ideology education workers. New media "civilian" and "grassroots" characteristics, condemned the user has "the authority". This is not just because everyone can easily obtain the corresponding information through new media means, and because of the contemporary college students tend to believe that their own independent judgment, they thought activity and no longer constrained to traditional thinking mode, often through new media to express their ideas and views. At the same time, in the new media era, college students with entertainment and a fragmented way of reading, reading all kinds of complex and profound social problems, the ideas of the traditional education emphasizes profundity, logical organization, content, comprehensive marginalized. Educated in learning new knowledge from habitual "asked the teacher," into a habitual "search baidu"; from the spread of the teachers "mainstream values", into a "track" even belief crisis; from the fear of the academic authority and look up, into a free and dismissive. In addition, the development of new media technology opened a "official corruption", "power rent-seeking" the FIG leaf of the dark side, such as, college students on the mainstream ideology education and their own specific thinking. In this background, the ideological and political education workers rely on information asymmetry avenues for professional knowledge, social experiences and practices the comparative advantages of the dominant discourse power is gradually weakened.

"Surreal" weakening the function of ideological and political education of college students' moral constraints. The spread of new media way with virtual features, users of the new media has stronger secretiveness, cause real life world and the virtual world different spiritual experience. Many people in the real world, dare not say words will not do are easy to find out of place in the virtual world. In the virtual world as VAT collected all kinds of information, the good and bad are intermingled by irrational network group and the pursuit of stimulation, the influence of the adventure curiosity, people are more likely to get rid of the social moral constraints, break through the social moral bottom line. College students' mental never mature to mature, personality didn't finalize the design to incline to finalize the design of key period, their world outlook, the outlook on life and values is more likely to be emotional, inflammatory information shake and hostage, combined with relevant laws and regulations is not yet perfect, the network supervision of all the difficulties, the network's "super realism" greatly weaken the ideological and political education work for college students' moral constraint function, make the body of the college students become extremely easily spread bad information, this undoubtedly give college students' ideological and political education work adds a great resistance.

\section{The countermeasures of ideological and political education of colleges and universities taken under the new media era}

The shift in thinking mode, to keep pace. College student workers should learn to change thinking mode, in corresponding to the traditional ideological and political education mode, on the basis of advancing with The Times, in an era of rapid development of new media, new areas to realize the network ideological and political education. Student workers should keep up the pace of new media related knowledge, be familiar with new media usage, change the traditional mode of thinking, new and old, rich forms of ideological and political education.

The establish information supervision mechanism, create a healthy network ideological and political education. Colleges and universities is to build a healthy and orderly network cultural environment, to strengthen the supervision and management of website, the establishment of a new 
campus media information management mechanism. Use of technical means in building information on the campus network and the network interface level, by setting up a network administrator, timely understanding of online information, some of the online harmful information filtering in time, shielding harm bad information of college students' psychology, thought, implement effective monitoring for new media information dissemination and reasonable guide. At the same time, education workers in colleges and universities should play the role of the organizers and managers, organizes the student cadre to supervise the school network information, including the post bar, QQ, Microblog, BBS, students WeChat etc., to spread bad information in the society and the students' improper comments do timely detection, timely delete, determined to cut off the spread of harmful information, build up health network environment.

To improve teachers' and students' media literacy. Media literacy refers to the public contact, interpret and use the quality and culture of the media, including three links: contact media, access to information; Reading media, critically accepted media information; Use media work and life, through the medium of sound and maintain their own interests. Against the phenomenon of information overflow, under the new media environment in colleges and universities must strengthen the guidance, improve teachers' and students' media literacy. Colleges and universities can use multiple channels to strengthen the cultivation of college students' media literacy, such as new media knowledge, moral and legal education can be penetrated into the course teaching, the knowledge or new media seminar, or open media literacy elective courses, cultivate and improve college students' awareness of harmful information resist consciously, critical and ability, make students establish a correct concept of new media.

\section{Summary}

In short, the new media's influence on ideological and political education has the characteristics of two sides; it brings to the ideological and political education work opportunities at the same time the challenges also allow not to ignore. We should dialectically treat the influence of new media, at the same time make full use of the advantage of new media, insist on Marxism culture occupy the network position, on the basis of constantly looking for new methods of ideological and political education, to strengthen ideological and political construction.

\section{References}

[1] Wang, Jia,Dai, Yanjun.Advanced Technology in Teaching. Proceedings of the20093rd International Conference on Teaching and Computational Science WTCS2009. 2012(6).

[2] Scott C.D' Urso. The Past, Present, and Future of Human Communication and Technology Research: An Introduction[J]. Journal of Computer - Mediated Communication. 2013(3).

[3] Barry Wellman,Janet Salaff,Dimitrina Dimitrova,Laura Garton,Milena Gulia,Caroline Haythornthwaite. Computer Networks As Social Networks: Collaborative Work, Telework, and Virtual Community[J]. Annual Review of Sociology. 2012(5).

[4] Dean R Spitzer.Super-Motivation: A Blueprint for Energizing Your Organization from Top to Bottom. Journal of Women s Health. 2012(6).

[5] Francis X Mahaney,Jr.Workplace Breast Cancer Screening Signals Shift inCorporate social responsibility. Journal of Women s Health. 2012(8). 